\title{
The effect of testing procedure on remember-know judgments
}

\author{
LAURA L. ELDRIDGE, STACEY SARFATTI, and BARBARA J. KNOWLTON \\ University of California, Los Angeles, California
}

\begin{abstract}
Remember-know (R-K) judgments are commonly used to assess conscious recollection of the study episode during recognition. We varied whether participants judged items as R, K, or new (one-step) or first made an old-new judgment and then made the R-K judgment (two-step). The one-step group had a higher $\mathrm{R}$ hit rate and $\mathrm{K}$ false alarm rate than did the two-step group. In addition, the $\mathrm{K}$ responses of the one-step group did not reliably discriminate between old and new items. When a "guess" response category was available, both groups were able to discriminate old and new items using the K response; however, $\mathrm{K}$ responses remained more accurate in the two-step condition. $\mathrm{R}$ responses appeared to be relatively immune to the effects of testing procedure when the guess category was provided. This suggests that, under some conditions, the $\mathrm{R}$ label can reliably indicate a distinct form of recognition memory, suggesting that allowing participants to use a guess response may help them to confine their R-Kjudgments to confidently recognized items. When participants are not given the option of making a guess response, they may use the R-K distinction to indicate the trace strength of the memory.
\end{abstract}

Participants in tests of recognition memory may report a sense of familiarity for previously studied items without conscious recollection of the encoding event. Such reports suggest that two forms of recognition exist: remembering, when recognition is accompanied by conscious recollection of the prior occurrence, and knowing, when recognition occurs with a sense of familiarity in the absence of conscious recollection(Tulving, 1985). Experimental results in which "remember" $(\mathrm{R})$ and "know" $(\mathrm{K})$ responses can be differentially manipulated support the idea that they reflect separate types of memory. For example, only $\mathrm{R}$ response rates are affected by levels of processing (Gardiner, 1988), divided attention (Gardiner \& Parkin, 1990), and word frequency manipulations (Gardiner \& Java, 1990), whereas K response rates are relatively unaffected. It is also possible to enhance the proportion of $\mathrm{K}$ responses while reducing the proportion of $\mathrm{R}$ responses, as is the case with recognition of nonwords relative to words (Gardiner \& Java, 1990).

Neurophysiological studies also support the idea that $\mathrm{R}$ and $\mathrm{K}$ judgments reflect qualitatively different forms of memory. Although evidence suggests that both R and K responses depend on the integrity of the medial temporal lobe (Knowlton \& Squire, 1995), it appears that other brain systems are differentially involved in the two types of recognition, as evidenced by event-related potential measurements (Smith, 1993) and fMRI (Eldridge, Knowlton, Furmanski, Bookheimer, \& Engel, 2000; Henson, Rugg,

L.L.E. was supported by an NSF graduate fellowship. The authors thank John Wixted, John Gardiner, Stephen Dewhurst, and William Hockley for valuable comments on earlier versions of this article. Correspondence should be addressed to B. J. Knowlton, Department of Psychology, UCLA, Los Angeles, CA 90095-1563 (e-mail: knowlton@ psych.ucla.edu).
Shallice, Josephs, \& Dolan, 1999). This suggests that separable brain regions may underlie these different forms of memory.

According to a contrasting view, the $\mathrm{R}-\mathrm{K}$ distinction does not represent two separate forms of recognition memory but instead may reflect differences in the strengths of memory traces (Donaldson, 1996). These accounts suggest that recognition and $\mathrm{R}-\mathrm{K}$ judgments can be made on the basis of implicit criteria separating weak and strong memory traces, rather than on the basis of distinguishable states of awareness (Hirshman \& Master, 1997). Thus, R responses simply reflect higher confidence recognition judgments (Donaldson, 1996; Hirshman, 1998; Hirshman \& Henzler, 1998). The trace-strength, or signal detection, model is generally able to account for dissociations between $\mathrm{R}$ and $\mathrm{K}$ response rates: Confidence is usually higher and false alarms are usually lower for $\mathrm{R}$ responses than for $\mathrm{K}$ responses.

Several recent studies have shown that $\mathrm{R}$ and $\mathrm{K}$ judgments can be very sensitive to manipulations affecting response criteria (Postma, 1999; Strack \& Förster, 1995). Thus, participants appear to apply the R-K labels differently depending on whether they are asked to be very conservative or liberal in calling items old or they are told that the majority of test items are targets or distractors. These results suggest that $\mathrm{R}$ and $\mathrm{K}$ responses correspond not to specific states of awareness but rather to levels of trace strength that are selected by participants on the basis of various decision criteria.

This view also received support from a study that showed that making the $\mathrm{R}-\mathrm{K}$ decision simultaneous with the recognition decision can affect performance on the $\mathrm{R}-\mathrm{K}$ task (Hicks \& Marsh, 1999). When both decisions are made in a single step, there are more hits and false alarms for both 
$\mathrm{R}$ and $\mathrm{K}$ responses than when participants first make the recognition decision and then indicate $\mathrm{R}$ and $\mathrm{K}$ for recognized items. These results support a trace-strength model, in that the increase in both hits and false alarms suggest that participants in the one-step condition used a more liberal criterion in making both $\mathrm{R}$ and $\mathrm{K}$ judgments than did participants in the two-step condition.

Although these studies suggest that $\mathrm{R}$ and $\mathrm{K}$ judgments can be operationalized as strong and weak memory, it is possible that participants apply the $\mathrm{R}$ and $\mathrm{K}$ labels this way when they have acquired few memories of the study session that are fully episodic (and thus would qualify as valid $\mathrm{R}$ responses). Previous research has suggested that only $\mathrm{R}$ response rates benefit from manipulations that enhance episodic encoding, including the use of low-frequency words (Gardiner \& Java, 1990) or more conceptually or perceptually distinctive words (Rajaram, 1998). In the Hicks and Marsh study, stimuli were common nouns that may not have given rise to many distinctive episodic memories that would qualify as valid $\mathrm{R}$ responses. It may be the case that participants are able to apply the $\mathrm{R}$ and $\mathrm{K}$ labels on the basis of their recollective state when they are able to retrieve clear episodic memories of studied items. If so, one would expect that factors that influence decision criteria would not greatly influence performance.

\section{EXPERIMENT 1}

The purpose of Experiment 1 was to examine the effect of instructions on R-K judgments under conditions in which episodic memory for specific items is enhanced. It is possible that the results from Hicks and Marsh (1999) were dependent on conditions discouraging episodic encoding. Under better episodic memory conditions, instructional manipulations may have little effect on performance, since participants may be able to operationalize the $\mathrm{R}-\mathrm{K}$ distinction as referring to episodic and nonepisodic memory rather than as measures of trace strength. Following Hicks and Marsh, we manipulated whether participants made the $\mathrm{R}-\mathrm{K}$ judgment after first making a recognition judgment (two-step instructions) or decided between R, K, or "new" (N) in a single judgment (one-step instructions). By using a relatively short study list that contained a high proportion of low-frequency words, we were able to examine the effect of $\mathrm{R}-\mathrm{K}$ instructions when episodic memory for individual items is relatively robust.

\section{Method}

Participants. The participants were 36 undergraduate students at the University of California, Los Angeles. An additional 9 participants were tested but were eliminated from the analysis because they failed to comply with instructions. Recruitment occurred on a voluntary basis, and the participants received class extra credit for their participation. They were randomly assigned to one of two groups. All participants were tested individually.

Materials and Design. A list of 72 six-letter words was generated (Gibson \& Watkins, 1988). Each word was printed in uppercase letters on a single $3 \times 5$ in. index card. Cards were divided equally into two stimulus sets (A and B) of 36 words, with each set having a mean frequency of 25 occurrences per million (Carroll, Davies, \&
Richman, 1971). Half of the words in each list had occurrences of fewer than 4 per million.

A $2 \times 2$ between-subjects design was used, with instructions (onestep vs. two-step instructions) and stimulus set (Set A vs. Set B) varying between participants.

Procedure. The participants were told that they would be shown a list of words that they should memorize for a test to be given later in the experiment. Each word was then presented for $2 \mathrm{sec}$, with all remaining words kept out of view of the participant. Card sets were shuffled between participants in order to randomize stimulus presentation.

During a subsequent 10 -min delay period, the participants were given a nonverbal distractor task of completing a visual pattern by selecting from among various alternatives (Raven, 1941). The participants were unaware of the objective of the distractor task; they were informed only that it was "a different type of test." The experimenter was not present in the testing room during this time.

Following the delay, the participants were given a recognition memory task for the original stimuli. In the memory test, the target words were combined randomly with the 36 words from the alternate stimulus set in four columns. The participants were instructed to work down the list using either one- or two-step instructions (described below). The two-step instructions were adapted from Gardiner and Java (1990) and Knowlton and Squire (1995) and were modified for the one-step version in accordance with the testing methods outlined by Yonelinas and Jacoby (1995). Both sets appear below.

\section{One-Step Instructions}

In this test there is a list of words; some of these words are from the cards you studied at the beginning of the experiment, others are not. Beside each word, please indicate whether or not you confidently recognize the word from the original study set, bearing in mind the following:

When we remember something, we consciously recollect and become aware of aspects of its occurrence. For example, you might remember a recent movie and be able to recall specific details about it, like where and with whom you saw it. At other times, we simply know that something has occurred before, but without being able to consciously recollect what was experienced at the time of its occurrence. For example, you might recognize a person and be certain that you know him or her, but be unable to recall any specific details about the person, such as the person's name.

For this test, remembering a word would signify that the word evokes specific memories of what was experienced during its presentation, such as how it looked on the card, the way in which it was presented, or even what you were thinking or doing at the time it was shown. Knowing a word would signify that you are confident the word appeared, but cannot recollect any aspects of its presentation.

Thus, in the space next to each word, please write $\mathrm{R}$ to show that you consciously recollect the occurrence of the word, $\mathrm{K}$ if you simply know that the word was in the original study set, or $\mathrm{N}$ if you think the word was not presented.

\section{Two-step Instructions}

The two-step instructions were identical to those above, with the exception of the first and final paragraphs. They were replaced by the following:

In this test there is a list of words; some of these words are from the cards you studied at the beginning of the experiment, others are not. As you work down the list, circle each word that you conf idently recognize from the study cards. Additionally, as you make your decision, bear in mind the following:

Thus, in the space next to each word you circled, please write R to show that you consciously recollect the occurrence of the word, or K if you feel you simply know that the word was in the original study set.

All participants were advised to work down the columns in order. The participants were then asked if they had any questions about 


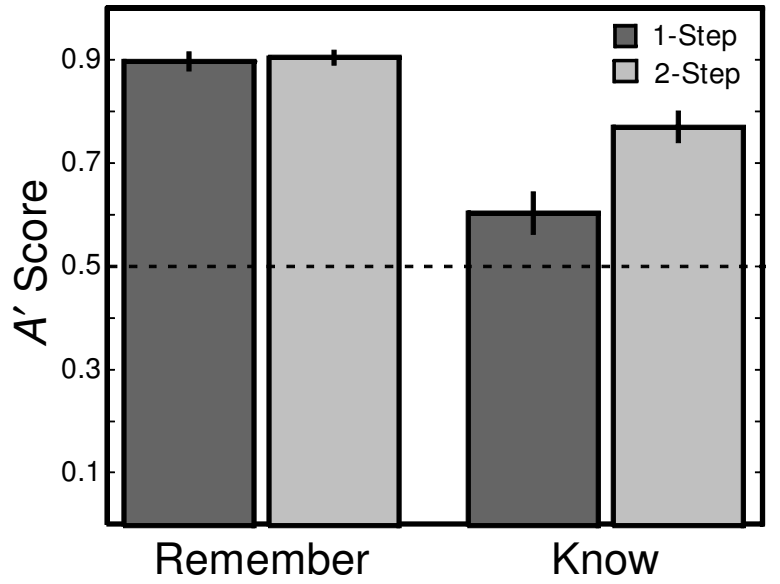

Figure 1. The mean $( \pm S E) A^{\prime}$ scores from Experiment 1 for "remember" and "know" responses as a function of the instruction group. Dotted line indicates chance performance.

how to proceed. For those who indicated that the R-K distinction was unclear, the experimenter reexplained the examples described in the instructions until the participants no longer demonstrated confusion. In order to verify participant compliance, the participants were asked at the conclusion of the task about their decision criteria for putting $\mathrm{R}$ or $\mathrm{K}$ ( or $\mathrm{N}$ ) next to a word. Data from the participants who were not able to justify their $\mathrm{R}$ or $\mathrm{K}$ responses or misinterpreted the $\mathrm{R}-\mathrm{K}$ distinction were excluded from the analysis (a total of 9 participants).

For each participant, the number of hits and false alarms for $\mathrm{R}$ and $\mathrm{K}$ were totaled, and an $A^{\prime}$ score (Swets, 1996) was calculated for each type of response.

\section{Results}

There were no differences in performance between the two stimulus lists ( $p s>.1$ ). Figure 1 shows $A^{\prime}$ scores (sensitivity) for items that were labeled $\mathrm{R}$ and $\mathrm{K}$ by the onestep and two-step groups. The overall recognition $A^{\prime} \operatorname{did}$ not differ by instruction group [one-step $=.93$; two-step $=.92$; $t(34)=0.37, p>.1]$.

However, the two-step group exhibited a higher $A^{\prime}$ for $\mathrm{K}$ responses than did the one-step group $[t(34)=2.91, p<.01]$. No corresponding difference between groups was found for $\mathrm{R}$ responses $[t(34)=0.19, p>.1]$. In the one-step group, the $\mathrm{K} A^{\prime}$ was not distinguishable from chance performance $[t(17)=1.48, p>.1]$. All other conditions led to performance that was reliably better than chance performance (all $p \mathrm{~s}<.01$ ). In addition, the overall recognition $A^{\prime}$ did not differ from the $\mathrm{R} A^{\prime}$ in either the one-step condi- tion or the two-step condition ( $p s>.1)$. We found that the criterion $\left(\lambda_{\text {center }}\right)$ for the recognition decision was reliably more conservative under the two-step instructions than under the one-step instructions [one-step $\lambda_{\text {center }}=-0.02$; two-step $\left.\lambda_{\text {center }}=0.56 ; t(34)=4.46, p<.01\right]$. The criterion for the $\mathrm{R}$ decision was also reliably more conservative under the two-step instructions than under the one-step instructions[one-step $\mathrm{R} \lambda_{\text {center }}=0.80$; two-step $\mathrm{R} \lambda_{\text {center }}=$ $1.24 ; t(34)=2.85, p<.01]$.

A $2 \times 2 \times 2$ (instruction group $\times$ response type $\times$ hits vs. false alarms) analysis of variance (ANOVA) was conducted (see Table 1). There were main effects of instruction group $[F(1,34)=16.16, p<.01]$, response type $[F(1,34)=15.70$, $p<.01]$, and hits versus false alarms $[F(1,34)=619.06$, $p<.01]$. There was an interaction of response type and hits versus false alarms $[F(1,34)=23.94, p<.01]$, which resulted from $\mathrm{R}$ responses being more accurate than $\mathrm{K}$ responses. There was also a significant three-way interaction $[F(1,34)=4.35, p<.05]$. Post hoc between-groups $t$ tests were performed on the marginal means. The number of $\mathrm{K}$ false alarms for the one-step group exceeded the corresponding total for the two-step group $[t(34)=3.34$, $p<.01]$. The number of $\mathrm{R}$ hits was also greater in the onestep group than in the two-step group $[t(34)=2.44, p<$ $.05]$.

\section{Discussion}

In Experiment 1, performance on the $\mathrm{R}-\mathrm{K}$ task was strongly influenced by whether the participants made the old-new and $\mathrm{R}-\mathrm{K}$ decisions in a single step or in two steps. The present results are consistent with the findings of a similar study by Hicks and Marsh (1999); although the one-step and two-step instructions were essentially identical, they resulted in very different patterns of performance.

The participants who were not required to make an initial recognition judgment prior to making an $\mathrm{R}$ or a $\mathrm{K}$ response were more prone to offer a $\mathrm{K}$ response for a word that did not appear in the original stimulus set. Since the $A^{\prime}$ score for $\mathrm{K}$ responses made in the one-step group was not significantly greater than chance (.50), it appears that the participants in the one-step group essentially did not discriminate between studied and unstudied items with K responses. In practical terms, the participants in the one-step group may have included more low trace-strength responses in the $\mathrm{K}$ category. This strategy misapplies the $\mathrm{K}$ label (Gardiner, 1988; Tulving, 1985), which is warranted only when one is confident that a stimulus appeared, but cannot attach this knowledge to any conscious memory. The

Table 1

Remember-Know Performance in Experiment 1

\begin{tabular}{|c|c|c|c|c|c|c|c|c|}
\hline \multirow[b]{2}{*}{ Condition } & \multicolumn{2}{|c|}{ RHit } & \multicolumn{2}{|c|}{ RFA } & \multicolumn{2}{|c|}{ KHit } & \multicolumn{2}{|c|}{ KFA } \\
\hline & $M$ & $S E M$ & $M$ & $S E M$ & $M$ & $S E M$ & $M$ & $S E M$ \\
\hline One-step & .62 & .06 & .04 & .01 & .20 & .04 & .11 & .02 \\
\hline Two-step & $.43^{*}$ & .04 & .02 & .00 & .26 & .04 & $.04^{*}$ & .01 \\
\hline
\end{tabular}

Note-RHit and RFA refer to hit and false alarm rates for items identified as remembered. KHit and KFA refer to items identified as known. *Difference from one-step level $(p<.05)$. 
performance of the participants in the two-step group was at least consistent with the strategy outlined by Tulving and Gardiner in that they were reliably able to discriminate old items from new items using both $\mathrm{R}$ and $\mathrm{K}$ responses.

In addition, the participants made more $\mathrm{R}$ hits under onestep instructions than under two-step instructions, whereas $\mathrm{K}$ hits did not differ under the two conditions. However, in the present experiment, there was no reliable effect of instructions on $\mathrm{R}$ false alarms, although the one-step procedure had a large effect on $\mathrm{K}$ false alarms. This suggests that $\mathrm{R}$ responses to lures may be consistently low under circumstances in which the participant has formed distinctive episodic memories for studied items.

The results from Experiment 1 are in many ways consistent with a trace-strength explanation of $\mathrm{R}-\mathrm{K}$ performance. According to this model, the increase in $\mathrm{R}$ hits and $\mathrm{K}$ false alarms with one-step instructions would be the result of the instructional manipulation causing a shift in decision criteria for the two responses. Consistent with this prediction, we found that both the recognition and $\mathrm{R}$ decision criteria became more liberal under the one-step instructions. By this view, one might expect an increase in $\mathrm{K}$ hits in the one-step condition. This effect may have been hidden by the relative increase in $\mathrm{R}$ hits. This could occur because the relaxation of the $\mathrm{R}$ criterion would result in items receiving $\mathrm{R}$ responses that would otherwise have received a $\mathrm{K}$ response. On the other hand, the lack of a reliable increase in $\mathrm{R}$ false alarms with the one-step instructions remains consistent with the idea that these responses reflect a qualitatively distinct type of memory in which the specific encoding context is reexperienced. Because episodic recollections are unlikely to occur for unexperienced events, one would expect the false alarm rate to be consistently low. In the present experiment, $\mathrm{R}$ responses may have been treated as something different than simply a high tracestrength memory because the participants were likely to have acquired distinctive episodic memories.

Similar to changing the decision-making process, the possible response alternatives may also influence performance of the task. A variation of the $\mathrm{R}-\mathrm{K}$ paradigm indicates that the $\mathrm{K}$ response category may be particularly sensitive to the addition of other response categories (Gardiner, Ramponi, \& Richardson-Klavehn, 1998; Gardiner, Richardson-Klavehn, \& Ramponi, 1997). In these studies, participants were given instructions regarding the proportion of studied and unstudied items that would manipulate response bias. At test, the participants could respond R, K, "guess" (G), or no recognition to each item. Although the manipulation of response bias had no effect on $\mathrm{R}$ and $\mathrm{K}$ responses, it did affect $\mathrm{G}$ responses. In contrast, a similar study that manipulated response bias but did not give participants the option of a $\mathrm{G}$ response found that $\mathrm{K}$ responses were affected by the manipulation (Strack \& Förster, 1995). These results suggest that giving participants the option of making $\mathrm{G}$ responses may influence whether or not $\mathrm{R}-\mathrm{K}$ is operationalized in terms of trace strength and could potentially reduce the effects of one- and two-step instructions on $\mathrm{R}$ and $\mathrm{K}$ responses.

\section{EXPERIMENT 2}

The purpose of Experiment 2 was to test the hypothesis that including a $\mathrm{G}$ response option would minimize the effects of one-step versus two-step instructions on response bias. Similar to Experiment 1, the decision-making process was manipulated by instructing the participants to make the $\mathrm{R}-\mathrm{K}-\mathrm{G}$ decision in either one-step or two-steps. Including the $\mathrm{G}$ category could potentially diminish the difference in $\mathrm{K}$ accuracy between the one and two step groups that was seen in Experiment 1. If the participants in the one-step condition were including low trace-strength items among their $\mathrm{K}$ responses, giving them the option of guessing should lead to fewer $\mathrm{K}$ response false alarms.

\section{Method}

Participants. The participants were 36 undergraduate students at the University of California, Los Angeles. One additional participant was tested but was eliminated from the analysis because of failure to comply with instructions. Recruitment occurred on a voluntary basis, and the participants received class extra credit for their participation. They were randomly assigned to one of two groups. All participants were tested individually.

Materials and Design. The lists of words from Experiment 1 were used in this experiment. Again, a $2 \times 2$ between-subjects design was used, with instructions (one-step vs. two-step instructions) and stimulus set (Set A vs. Set B) varying between participants.

Procedure. The participants received the same study and distractor phase instructions as in Experiment 1. The instructions for the test phase were modified from Experiment 1 to include a $G$ response category in both the one-step group and the two-step group. The final paragraphs of the one-step instructions were modified to include the following:

\footnotetext{
There will also be times when you do not remember the word, nor do you know it, but you might want to guess that it was one of the words you saw on the study list.

Thus, in the space next to each word, please write R to show that you consciously recollect the occurrence of the word, $\mathrm{K}$ if you simply know that the word was in the original study set, $\mathrm{G}$ if you're guessing that the word was studied, or $\mathrm{N}$ if you think the word was not presented.
}

The final paragraph of the two-step instructions from Experiment 1 was modified to state:

Thus, in the space next to each word you circled, please write $\mathrm{R}$ to show that you consciously recollect the occurrence of the word, or $\mathrm{K}$ if you feel you simply know that the word was in the original study set. Beside words that you did not circle, please write $\mathrm{G}$ if they are words that you didn't confidently recognize, but you guess that they could have been in the study set.

The same procedure was used for instructing the participants to complete the test as in Experiment 1. Data from the participants who were not able to justify their $\mathrm{R}$ or $\mathrm{K}$ responses or misinterpreted the $\mathrm{R}-\mathrm{K}$ distinction were excluded from the analysis (1 participant).

For each participant, the number of hits and false alarms for $\mathrm{R}$ and K were totaled, and an $A^{\prime}$ score (Swets, 1996) was calculated for each type of response.

\section{Results}

There were no differences in performance between the two stimulus lists ( $p s>.1$ ). Figure 2 shows $A^{\prime}$ scores for items that were labeled $\mathrm{R}, \mathrm{K}$, and $\mathrm{G}$ by the one-step and two-step groups. The overall recognition $A^{\prime}$ was lower for the one-step group than for the two-step group [one-step 


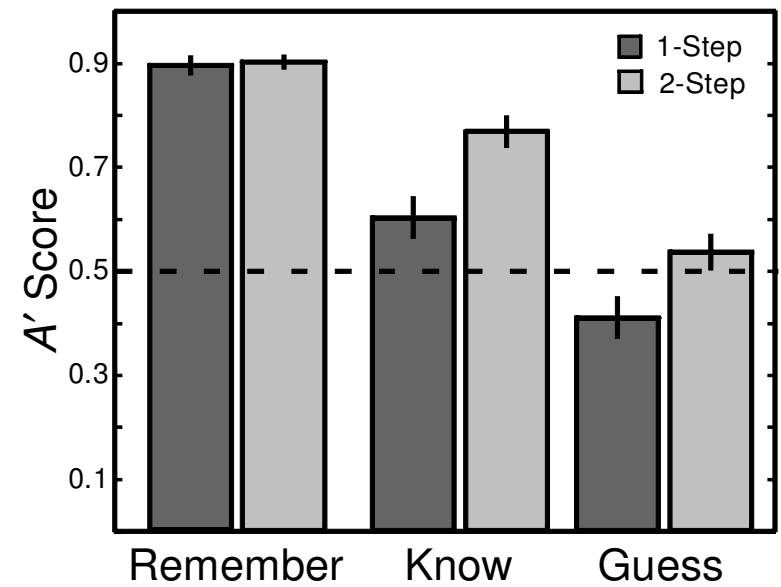

Figure 2. The mean $( \pm S E) A^{\prime}$ scores from Experiment 2 for "remember," "know," and "guess" responses as a function of the instruction group. Dotted line indicates chance performance.

$=.84 ;$ two-step $=.90 ; t(34)=2.26, p<.05]$. The instructions did not have a reliable effect on $\mathrm{R} A^{\prime}[t(34)=0.32$, $p>.1]$. However, the $\mathrm{K} A^{\prime}[t(34)=3.34, p<.01]$ and the $\mathrm{G} A^{\prime}[t(34)=2.43, p<.05]$ were reliably lower under the one-step instructions than under the two-step instructions. In the two-step condition, the $\mathrm{G} A^{\prime}$ did not differ from chance $[t(17)=1.13, p>.1]$, whereas in the one-step condition the $\mathrm{G} A^{\prime}$ was reliably lower than chance $[t(17)=2.3$, $p<.05]$. All other conditions led to performance that was reliably better than chance performance (all $p \mathrm{~s}<.05$ ). In addition, the overall recognition $A^{\prime}$ differed from the $\mathrm{R} A^{\prime}$ only in the one-step condition $[t(17)=2.24, p<.05]$. The criterion $\left(\lambda_{\text {center }}\right)$ for the recognition decision was reliably more conservative under the two-step instructions than under the one-step instructions [one-step $\lambda_{\text {center }}=-0.20$; two-step $\left.\lambda_{\text {center }}=0.28 ; t(34)=3.97, p<.01\right]$. However, the criterion for the $\mathrm{R}$ decision did not reliably differ between the two instruction groups [one-step $\mathrm{R} \lambda_{\text {center }}=0.95$; twostep $\left.\mathrm{R} \lambda_{\text {center }}=1.10 ; t(34)=1.18, p>.2\right]$.

A $2 \times 2 \times 2$ (instruction group $\times$ response type $\times$ hits vs. false alarms) ANOVA was also conducted (see Table 2). There were main effects of instruction group $[F(1,34)=$ $16.18, p<.01]$, response type $[F(1,34)=30.46, p<.01]$, and hits versus false alarms $[F(1,34)=450.54, p<.01]$. There was an interaction of instructions and hits versus false alarms $[F(1,34)=4.64, p<.05]$. This resulted from the fact that the two-step group had a lower false alarm rate than did the one-step group. Post hoc between-groups $t$ tests showed that the number of false alarms for the onestep group exceeded the corresponding total for the twostep group only for $\mathrm{K}[t(34)=3.23, p<.01]$ and $\mathrm{G}[t(34)=$ $3.37, p<.01]$ responses. There was an interaction of response type and hits versus false alarms $[F(1,34)=78.85, p<.01]$, which resulted from $\mathrm{R}$ responses being more accurate than $\mathrm{K}$ responses and $\mathrm{G}$ responses.

\section{Discussion}

The aim of Experiment 2 was to examine whether providing participants with a "guess" response category would influence the operationalization of the $\mathrm{R}$ and $\mathrm{K}$ categories. In Experiment 1, it appeared that the participants in the one-step group were more prone to treat $\mathrm{K}$ responses as guesses because the $\mathrm{K}$ hit rate was not reliably greater than the $\mathrm{K}$ false alarm rate. Similarly, in Experiment 2, the $\mathrm{K}$ false alarm rate remained reliably larger in the one-step group than in the two-step group, whereas there was no difference in the $\mathrm{K}$ hit rates. Although the $\mathrm{G}$ category did not eliminate the difference in $\mathrm{K}$ accuracy between groups, it did appear to improve $\mathrm{K}$ accuracy in the onestep group. Provided with the $G$ response alternative, the participants in the one-step condition were able to reliably discriminate old items from new items with the $\mathrm{K}$ response.

In contrast to the effect on K responses, the participants' $\mathrm{R}$ responses were unaffected by the instruction manipulation. $\mathrm{R}$ responses did not differ in accuracy between the one- and two-step groups; both hit and false alarm rates were at similar levels across groups. The increase in $\mathrm{R}$ hits seen in the one-step group in Experiment 1 was not replicated. Also in contrast to Experiment 1, there was not a reliable shift in the $\mathrm{R}$ decision criterion due to instructions, although the recognition decision criterion did become more liberal under one-step instructions.

The accuracy of the participants' $G$ responses was greatly affected by instructions. Although neither group was discriminating at levels reliably better than chance using the $\mathrm{G}$ response, $\mathrm{G}$ discrimination was somewhat better in the two-step group than in the one-step group. In fact, the accuracy of $\mathrm{G}$ responses was reliably lower than chance in the one-step group. The difference in accuracy between groups was the result of a higher false alarm rate in the one-step group. The findings suggest that the decisionmaking instructions influence the likelihood that unstudied items will be endorsed as $\mathrm{K}$ responses or guesses.

Table 2

Remember-Know-Guess Performance in Experiment 2

\begin{tabular}{|c|c|c|c|c|c|c|c|c|c|c|c|c|}
\hline \multirow[b]{2}{*}{ Condition } & \multicolumn{2}{|c|}{ RHit } & \multicolumn{2}{|c|}{ RFA } & \multicolumn{2}{|c|}{ KHit } & \multicolumn{2}{|c|}{ KFA } & \multicolumn{2}{|c|}{ GHit } & \multicolumn{2}{|c|}{ GFA } \\
\hline & $M$ & SEM & $\bar{M}$ & $S E M$ & $M$ & $S E M$ & $M$ & SEM & $M$ & $S E M$ & $M$ & $S E M$ \\
\hline One-step & .53 & .05 & .04 & .01 & .18 & .04 & .09 & .02 & .11 & .02 & .18 & .03 \\
\hline Two-step & .46 & .04 & .02 & .01 & .19 & .03 & $.02 *$ & .01 & .08 & .01 & $.07 *$ & .02 \\
\hline
\end{tabular}

Note-RHit and RFA refer to hit and false alarm rates for items identified as remembered. KHit and KFA refer to items identified as known. GHit and GFA refer to items identified as guess. *Difference from one-step level $(p<.05)$. 
The present results do not completely confirm the predictions generated by the results of Experiment 1 . Although the $\mathrm{G}$ category did appear to improve $\mathrm{K}$ accuracy in the onestep group, it did not improve $\mathrm{K}$ accuracy to levels achieved in the two-step group. The overall effect of response alternatives on K accuracy suggests that the one-step versus two-step instructions have a significant impact on the way that $\mathrm{K}$ responses are operationalized, and it does not appear that simply giving participants the option of guessing will override the effect of decision-making instructions. These results are in contrast with those of Gardiner et al. (1997), in which the inclusion of a guess response option eliminated the effect of bias on $\mathrm{K}$ response rates. It may be that the one- and two-step instructions affect participants' decision making in a way that is different from leading them to believe that there are higher numbers of studied or unstudied items.

The results of Experiment 2 do not fit neatly with either a quantitative or a qualitative account of the difference between $\mathrm{R}$ and $\mathrm{K}$ responses. Although the influence of instructions on $A^{\prime}$ scores was limited to $\mathrm{K}$ and $\mathrm{G}$ responses, consistent with predictions of a trace-strength model (Hirshman, 1998), a key prediction of the model was not confirmed. In particular, the $A^{\prime}$ for R responses in the one-step condition was reliably greater than the corresponding $A^{\prime}$ for overall recognition performance, suggesting that $\mathrm{R}$ responses are not simply higher threshold responses but may reflect distinct mnemonic processes. However, the present results are also not entirely consistent with the view that $\mathrm{R}$ and $\mathrm{K}$ responses reflect distinct states of awareness. This model would predict that both $\mathrm{R}$ and $\mathrm{K}$ responses should be relatively robust to the effect of instructions, because participants should be able to consistently apply those labels to distinct forms of memory. However, $\mathrm{K}$ responses to lures were extremely sensitive to response instructions, even when the participants were given the opportunity to label items as guess responses.

\section{GENERAL DISCUSSION}

Overall, we found that the way that participants are instructed to make the $\mathrm{R}-\mathrm{K}$ decision can have an important effect on their performance. In Experiment 1, response instructions affected $\mathrm{R}-\mathrm{K}$ performance in a manner that was largely consistent with the idea that the difference in memories labeled as $\mathrm{R}$ and $\mathrm{K}$ lies in the difference in the strengths of those memory traces. However, in Experiment 2, providing the participants with the option of guessing may have changed the way that $\mathrm{R}$ responses were operationalized so that they no longer simply reflected stronger memory traces. This suggests that instructions and response alternatives can affect the way that participants are using these labels, rather than simply biasing their responses.

Because specific episodic recollections are unlikely to occur for unstudied items, $\mathrm{R}$ false alarm rates should be consistently low, despite bias manipulations. Across both experiments, $\mathrm{R}$ responses to lures were infrequent and did not increase significantly with one-step instructions. In con- trast, $\mathrm{K}$ responses to lures were consistently more frequent under the one-step instructions. Thus, it appears that judgments about familiarity are extremely sensitive to whether or not the participant is first asked to confidently recognize items.

One possible interpretation of the present results is that both quantitative and qualitative differences in the memories could contribute to performance on the R-K task. K responses appear to be vulnerable to manipulationsthat shift the response criteria, whereas $\mathrm{R}$ responses are relatively more robust to these manipulations. $R$ responses may reflect a distinct form of memory, in that they are accompanied by specific recollections of the encoding episode. Neuroimaging results are consistent with this idea, in that only $\mathrm{R}$ responses are accompanied by activation in the hippocampus (Eldridge et al., 2000). K (and G) responses are based on assessments of familiarity, a continuous variable that is a property of both targets and lures. $\mathrm{K}$ and $\mathrm{G}$ responses can be described in terms of a trace-strength model, whereas recollection is a separate process that contributes to recognition performance. This interpretation is consistent with the dual-process framework described by Yonelinas (1994).

Another possibility is that the instruction manipulation itself influenced whether the participants responded on the basis of trace strength or on the basis of qualitative differences between memories. Information about strength may be the most salient aspect of a memory trace and thus may be the information most accessible to metacognitive judgments. When participants are making only a single judgment, the readily available trace-strength information may have a primary influence, with high-strength items receiving $\mathrm{R}$ responses and lower strength items receiving $\mathrm{K}$ responses. The two-step instructions may have allowed the participants to better evaluate the contents of each memory by separating the $\mathrm{R}-\mathrm{K}$ decision from the old-new decision. The fact that, in Experiment 2, there was a significant difference in the overall $A^{\prime}$ score between the instruction conditions is consistent with the idea that participants are approaching the test differently in the two conditions.

Another reason for the differences between instruction conditions could be that the one-step instructions required the participants to make a response for every item. The participants may have been reluctant to give the $\mathrm{N}$ response alternative to more than half of the items. In the two-step condition, unrecognized items did not receive a response and were simply left blank. In both experiments, there were consistently fewer $\mathrm{N}$ responses in the one-step condition than there were unrecognized items in the two-step condition $(p \mathrm{~s}<.001)$. A tendency to use the $\mathrm{N}$ response less often could have led to a criterion shift between the two conditions.

The results of both experiments support the idea that $\mathrm{K}$ responses can be readily influenced by the demand characteristics of the task. A manipulation as subtle as influencing whether the participants made the recognition and $\mathrm{R}-\mathrm{K}$ decision in one or two steps greatly influenced the accuracy of those judgments. It seems likely that this vari- 
ability in response accuracy reflects an underlying difference in how participants are using the $\mathrm{K}$ response. Even giving participants the opportunity to guess does not reverse the effect of instruction on $\mathrm{K}$ responses, although it does appear to improve $\mathrm{K}$ discriminability somewhat.

The present results, as well as those of Hicks and Marsh (1999), underscore the importance of using the two-step procedure in studies that use the $\mathrm{R}-\mathrm{K}$ distinction. In the original $\mathrm{R}-\mathrm{K}$ recognition test, participants first indicated which words they confidently recognized as having been studied and then assigned an $\mathrm{R}$ or a $\mathrm{K}$ response to each recognizeditem (Tulving, 1985). However, other researchers have used variations of this original procedure, which may influence performance. For example, participants have been instructed to answer $\mathrm{R}, \mathrm{K}$, or $\mathrm{N}$ in a single judgment (Brewer, Zhao, Desmond, Glover, \& Gabrieli, 1998; Henson et al., 1999; Yonelinas \& Jacoby, 1995), thus eliminating an initial recognition judgment prior to the R-K decision. This modification may induce participants to treat $\mathrm{R}-\mathrm{K}$ judgments as measures of confidence.

In conclusion, the findings presented here recommend that researchers adhere to a standard $\mathrm{R}-\mathrm{K}$ procedure. In order to ensure that the $\mathrm{K}$ response category is not used for guesses only, it may be useful to employ the procedure that Tulving (1985) originally formulated, in which R and K judgments are made only for those items initially judged as confidently recognized. Failure to do so may further cloud the issue of whether the $\mathrm{R}-\mathrm{K}$ distinction is a useful construct in memory research. In addition, the inclusion of a $\mathrm{G}$ response category may also help to encourage more accurate $\mathrm{K}$ responses. Finally, R responses may be applied with greater validity when study conditions encourage the formation of distinct episodic memories for individual items.

\section{REFERENCES}

Brewer, J. B., Zhao, Z., Desmond, J. E., Glover, G. H., \& GABRIELI, J. D. E. (1998). Making memories: Brain activity that predicts how well visual experience will be remembered. Science, 281, 1185-1187.

Carroll, J. B., Davies, P., \& Richman, B. (1971). Word frequency book. New York: American Heritage.

DonaldSON, W. (1996). The role of decision processes in remembering and knowing. Memory \& Cognition, 24, 523-533.

Eldridge, L. L., Knowlton, B. J., Furmanski, C. S., Bookheimer,S. Y., \& ENGEL, S. A. (2000). Remembering episodes: A selective role for the hippocampus during retrieval. Nature Neuroscience, 3, 1149-1152.

GARDINER, J. M. (1988). Functional aspects of recollective experience. Memory \& Cognition, 16, 309-313.
GARdiner, J. M., \& JAVA, R. I. (1990). Recollective experience in word and nonword recognition. Memory \& Cognition, 18, 23-30.

Gardiner, J. M., \& PArkin, A. J. (1990). Attention and recollective experience in recognition memory. Memory \& Cognition, 18, 579-583.

Gardiner, J. M., Ramponi, C., \& Richardson-Klavehn, A. (1998). Experiences of remembering, knowing, and guessing. Consciousness \& Cognition, 7, 1-26.

Gardiner, J. M., Richardson-Klavehn, A., \& Ramponi, C. (1997). On reporting recollective experiences and "direct access to memory systems.” Psychological Science, 8, 391-394.

Gibson, J. M., \& WatKins, M. J. (1988). A pool of 1,086 words with unique two-letter fragments. Behavior Research Methods, Instruments, \& Computers, 20, 390-397.

Henson, R. N. A., Rugg, M. D., Shallice, T., Josephs, O., \& Dolan, R. J. (1999). Recollection and familiarity in recognition memory: An event-related functional magnetic resonance imaging study. Journal of Neuroscience, 19, 3962-3972.

Hicks, J. L., \& MARSH, R. L. (1999). Remember-know judgments can depend on how memory is tested. Psychonomic Bulletin \& Review, 6, 117-122.

Hirshman, E. (1998). On the utility of the signal detection model of the remember-know paradigm. Consciousness \& Cognition, 7, 103-107.

Hirshman, E., \& Henzler, A. (1998). The role of decision processes in conscious recollection. Psychological Science, 9, 61-65.

Hirshman, E., \& MASTER, S. (1997). Modeling the conscious correlates of recognition memory: Reflections on the remember-know paradigm. Memory \& Cognition, 25, 345-351.

Knowlton, B. J., \& SQuire, L. R. (1995). Remembering and knowing: Two different expressions of declarative memory. Journal of Experimental Psychology: Learning, Memory, \& Cognition, 21, 699-710.

Post ma, A. (1999). The influence of decision criteria upon remembering and knowing in recognition memory. Acta Psychologica, 103, 65-76.

RAJARAM, S. (1998). The effects of conceptual salience and perceptual distinctiveness on conscious recollection. Psychonomic Bulletin \& Review, 5, 71-78.

RAVEN, J. C. (1941). Standardization of progressive matrices. British Journal of Medical Psychology, 19, 137-150.

Smith, M. E. (1993). Neurophysiological manifestations of recollective experience during recognition memory judgments. Journal of Cognitive Neuroscience, 5, 1-13.

Strack, F., \& FörSTER, J. (1995). Reporting recollective experiences: Direct access to memory systems? Psychological Science, 6, 352-358.

SwETS, J. A. (1996). Signal detection theory and ROC analysis in psychology and diagnostics. Hillsdale, NJ: Erlbaum.

Tulving, E. (1985). Memory and consciousness. Canadian Psychology, 26, 1-12.

YonELINAS, A. P. (1994). Receiver-operating characteristics in recognition memory: Evidence for a dual process model. Journal of Experimental Psychology: Learning, Memory, \& Cognition, 20, 1341-1354.

YonelinAs, A. P., \& JACOBY, L. L. (1995). The relation between remembering and knowing as bases for recognition: Effects of size congruency. Journal of Memory \& Language, 34, 622-643.

(Manuscript received August 17, 1999; revision accepted for publication May 11,2001.) 